\title{
Under Reporting of ADRs by Medical Practitioners in India - Results of Pilot Study
}

\section{Rakesh Kumar Rishi', Rakesh K. Patel ${ }^{2 *}$, and Anil Bhandari ${ }^{3}$}

${ }^{1}$ Head of Department of Pharmacology, Central Drugs Laboratory, Ministry of Health \& Family Welfare, Govt. of India, 3, Kyd Street, Kolkata - 700016 ${ }^{2}$ Professor and Head, Department of Pharmacognosy, S.K.Patel College of Pharmaceutical Education \& Research, Ganpat University, Kherva- 382 711, Mehsana, Gujarat, India

${ }^{3}$ Principal, Jodhpur Pharmacy College, Jhanwar Road, Boranada, Jodhpur, Rajasthan-342 001

\begin{abstract}
Spontaneous reporting of adverse drug reactions (ADRs) is an important method in pharmacovigilance, but under-reporting and poor qualities of reports are major limitations. The aim of this study was to investigate reasons for under-reporting of ADRs by the medical practitioners in India. The opinion of physicians on the under-reporting of ADRs was assessed by self administered, anonymous questionnaire. In this pilot study, a total of 100 doctors across the country responded to the questionnaire. A total of $81 \%$ of the respondents were males and the rest $19 \%$ were females with average age of 43.54 years. The surveyed physicians were from different backgrounds and they were having different medical qualifications. Vast majority of respondents $(96 \%)$ stated that all drugs available in the market are not safe and $86 \%$ stated that they had experienced ADRs in patients. A total of $95 \%$ agreed that ADRs should be reported by the medical practitioners and 96\% stated that ADR reporting and monitoring system would benefit the patient. The practitioners were allowed to select more than one reason for under reporting in the study questionnaire in this pilot study. All the practitioners cited one or the other reason for under-reporting. A total of 328 responses were obtained from 100 medical practitioners (average response 3.28 per medical practitioner). Our study suggests incorporating more training on pharmacovigilance to the willing physicians emphasizing more on the importance of training of reporting. It is also concluded that there is an urgent need to do more research to improve the understanding of the barriers to reporting ADRs and how they may be overcome.
\end{abstract}

Keywords: Adverse Drug Reactions (ADRs); Pharmacovigilance; ADR reporting; Attitude; Knowledge

\section{Introduction}

The systems for spontaneous reporting of Adverse Drug Reactions (ADRs) were developed in the 1960s [1] and are currently recognized as the foundation of postmarketing surveillance of drug safety $[2,3]$. The spontaneous reporting system is a critical component of the early warning system for unknown and rare ADRs [4]. Other objectives include identification of risk factors associated with known ADRs, as well as information regarding increased frequency and/or severity for known ADRs [5]. Despite the acceptance of spontaneous reports as a critical and crucial method for the post-approval assessment of ADRs, serious limitations, including both under-reporting and inadequate quality of data, have been associated with the reports. Globally, underreporting of ADRs is a major problem and India is not an exception to it. It is therefore crucial to encourage health care providers around the world to report ADRs. Many factors are reported to be associated with under-reporting of ADRs by health care professionals who have been broadly classified as personal and professional characteristics of health careers, and their knowledge and attitudes to reporting [2]. For many different reasons (such as lack of knowledge, lack of awareness of pharmacovigilance systems, heavy work load, hesitation in making the correct decision), health care professionals do not report ADRs as frequently as expected [6]. Other study also reported several reasons for underreporting of ADRs such as busy schedule, misconceptions about spontaneous ADR reporting and bureaucratic reporting procedures, lack of information on how to report and a lack of availability of report forms, and physicians' attitudes to ADRs [2]. The main objective of this pilot study was to assess the attitude of the Indian medical practitioners towards ADR reporting and to evaluate their knowledge of the spontaneous reporting system as well as to identify the reasons for low reporting rate so that suitable interventions may be planned in future in order to improve the reporting culture.

\section{Methods}

In this pilot study, self administered questionnaire was prepared after consultation with experts in the field of pharmacovigilance and studying relevant scientific literature. Randomly chosen 100 doctors across the country were requested to fill the study questionnaire. The demographic information, level of education and training of the Indian medical practitioners as well as opinion on under-reporting was obtained through study questionnaire. The present pilot study had been carried out to finalize and validate the prepared questionnaire format before its inclusion and application for the larger group for the main study comprising with at least 1000 doctors from different states of India.

Before analysis, the collected data was anonymised. The questionnaire developed and validated through this pilot study will also be incorporated as such to the main ongoing pharmacoepiemological study. Therefore, all the data collected through this pilot study will also be included to the main data of the ongoing final study for analysis and interpretation purpose. The collected data has been analysed through standard statistical methods.

*Corresponding author: Rakesh Kumar Rishi, Head of Department of Pharmacology, Central Drugs Laboratory, Ministry of Health \& Family Welfare, Govt. of India, 3 Kyd Street, Kolkata-700 016, India, E-mail: rkrishi@yahoo.com

Received May 03, 2012; Accepted June 21, 2012; Published June 26, 2012

Citation: Rishi RK, Patel RK, Bhandari A (2012) Under Reporting of ADRs by Medical Practitioners in India - Results of Pilot Study. Adv Pharmacoepidem Drug Safety 1:112. doi:10.4172/2167-1052.1000112

Copyright: ( 2012 Rishi RK, et al. This is an open-access article distributed unde the terms of the Creative Commons Attribution License, which permits unrestricted use, distribution, and reproduction in any medium, provided the original author and source are credited. 


\section{Results}

The survey questionnaire was analyzed question wise and their percentagevalue wascalculated. In this pilotstudy, a total of 100 physicians from various parts of the country responded to the questionnaire. Since it is a large scale ongoing pharmacoepidemiological study, results of all parameters are not presented in this paper. A total of $81 \%$ of the respondents were males and the rest $19 \%$ were females. Average age of the physicians was 43.54 years (maximum 66 years; minimum 24 years) (Table 1). The physicians were from different backgrounds (see figure 1). They were having different medical qualifications such as M.D. (44\%), M.B.B.S. (25\%), M.S. (17\%), D.M. (6\%), Ph.D. (3\%), M.D.S. (2\%), M.C.H. (1\%), D.N.B. (1\%), and D.C.H. (1\%). A total of 15 Indian states were covered for collecting data from 100 physicians in this pilot study. These states and their respective number of respondents (given in brackets) were Andhra Pradesh (2), Assam (2), Chandigarh (1), Delhi (17), Gujarat (5), Haryana (4), Jammu \& Kashmir (6), Jharkhand (3), Karnataka (17), Kerala (7), Madhya Pradesh (2), Maharashtra (8), Rajasthan (10), Tamil Nadu (1), and West Bengal (15).

Vast majority of respondents (96\%) stated that all drugs available in the market are not safe (Table 2). Majority of the physicians (86\%) stated that they had experienced ADRs in patients while $14 \%$ stated that they did not experience ADRs during their practice. When asked "have you ever experienced an ADR in patients during your practice?", $86 \%$ stated yes and $14 \%$ stated no. Majority of the respondents (81\%) stated that 10 to $20 \%$ patients complain about ADRs while $7 \%$ stated as nil. Others stated that 21 to $40 \%(10 \%)$ and more than $50 \%(2 \%)$ of the patients complain about ADRs. Majority of the respondents (95\%) agreed that ADRs should be reported by the medical practitioners and

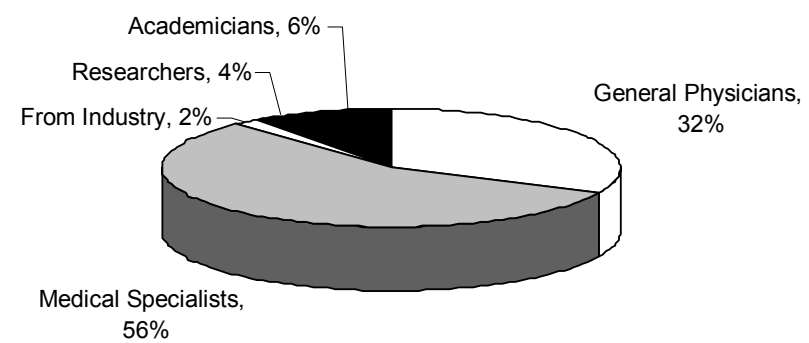

Figure 1: Different backgrounds of the surveyed population.

\begin{tabular}{|l|l|l|l|l|l|l|l|l|l|}
\hline Variables & \multicolumn{4}{|l|}{ Age (Years) } & \multicolumn{3}{l|}{ Sex } & \multicolumn{2}{l|}{ Experience (Years) } \\
\hline Parameter & Mean & SD & Max. & Min. & Males & Females & Average & Max.) & Min. \\
\hline Value & 43.54 & 11.41 & 66 & 24 & $81 \%$ & $19 \%$ & 16.07 & 40 & 1 \\
\hline
\end{tabular}

Table 1: Demographic characteristics of the study population $(n=100)$.

\begin{tabular}{|l|l|l|l|}
\hline Question & Yes & No & Don't Know \\
\hline $\begin{array}{l}\text { Do you believe all drugs available in the } \\
\text { market are safe? }\end{array}$ & $1 \%$ & $96 \%$ & $3 \%$ \\
\hline $\begin{array}{l}\text { Have you ever experienced an Adverse } \\
\text { Drug Reaction (ADR) in patients during your } \\
\text { practice? }\end{array}$ & $86 \%$ & $14 \%$ & $*$ \\
\hline \begin{tabular}{l} 
Should ADRs be reported by physicians? \\
\hline $\begin{array}{l}\text { Do you think that ADR reporting and monitor- } \\
\text { ing system would benefit the patient? }\end{array}$
\end{tabular} & $96 \%$ & $1 \%$ & $4 \%$ \\
\hline
\end{tabular}

*Parameter not included in the study questionnaire.

Table 2: Opinion of physicians regarding safety of drugs and ADR reporting $(n=100)$.

\begin{tabular}{|l|l|l|l|}
\hline S. No. & Reason & Response* $(\mathrm{n}=328)^{\text {Response* }}$ (\%) \\
\hline 1 & $\begin{array}{l}\text { Only safe drugs are available on } \\
\text { the market }\end{array}$ & 8 & 2.4 \\
\hline 2 & $\begin{array}{l}\text { Reporting does not influence the } \\
\text { treatment scheme }\end{array}$ & 18 & 5.5 \\
\hline 3 & Busy schedule & 73 & 22.3 \\
\hline 4 & Lack of incentives & 29 & 8.8 \\
\hline 5 & $\begin{array}{l}\text { Physician should rather collect } \\
\text { data and publish himself/herself }\end{array}$ & 16 & 4.9 \\
\hline 6 & $\begin{array}{l}\text { Difficult to pin point suspected } \\
\text { drug }\end{array}$ & 33 & 10.1 \\
\hline 7 & ADR is known to physician & 15 & 4.6 \\
\hline 8 & Don't know whom to report & 45 & 13.7 \\
\hline 9 & Reporting could show ignorance & 16 & 4.9 \\
\hline 10 & $\begin{array}{l}\text { Difficult to admit harm to the } \\
\text { patient }\end{array}$ & 14 & 4.3 \\
\hline 11 & Insufficient clinical knowledge & 20 & 6.1 \\
\hline 12 & $\begin{array}{l}\text { Thinking one report doesn't make } \\
\text { difference }\end{array}$ & 34 & 10.4 \\
\hline 13 & Others & 7 & 2.1 \\
\hline
\end{tabular}

\section{*Multiple responses}

Table 3: Reasons cited by physicians for under reporting of ADRs $(n=100)$.

96\% stated that ADR reporting and monitoring system would benefit the patient (Table 2).

The practitioners were allowed to select more than one reason for under reporting in the study questionnaire in this pilot study. Interviewed doctors were allowed to give multiple answers and in order to get the maximum possible responses, no limit of answers were kept. All the practitioners cited one or the other reason for under-reporting. A total of 328 responses were obtained from 100 medical practitioners (average response 3.28 per medical practitioner). Various causes of under-reporting of ADRs cited by the practitioners include: only safe drugs are available on the market (2.4\%); reporting does not influence the treatment scheme (5.5\%); busy schedule (22.3\%); lack of incentives (8.8\%); physician should rather collect data and publish himself/herself (4.9\%); difficult to pin point suspected drug (10.1\%), ADR is known to physician (4.6\%); don't know whom to report (13.7\%); reporting could show ignorance $(4.9 \%)$, difficult to admit harm to the patient $(4.3 \%)$; insufficient clinical knowledge (6.1\%); thinking one report doesn't make difference (10.4\%). A total of 7 respondents $(2.1 \%)$ cited other reasons for under-reporting which included negligence, apathy and general casualness, nobody wants to take responsibility and be named, fear of legal action, carelessness, and co-administration of drugs (Table $3)$.

\section{Discussion}

The main strength of the ADR reporting scheme is that it enables continuous and spontaneous monitoring on the use of a product throughout its life span by all patients. Despite the fact that the ADR reporting is an old concept, ADRs are significantly under-reported all over the world and our study reveals that India is no exception to it. To the best of knowledge of the authors, there have been no formal studies carried out to capture data on under-reporting in India with a particular focus on reasons of under-reporting. The present work was a humble attempt to study the same. Compared to other countries, the number of spontaneous reports submitted in the UK is relatively high and reporting rates in relation to prescription volumes are also among the best in Europe [7]. It is estimated, however, that only $10 \%$ of serious reactions and between 2 and 4 percent of non-serious reactions are reported8. Such a high level of under-reporting will necessarily 
lead to bias in the data collected via the National Pharmacovigilance Programmes. Our study findings revealed several factors that influenced the Indian physicians from reporting ADRs. A study reported several factors that were considered as contributing factors for not reporting suspected ADRs included lack of time, well-known reactions, mild adverse reactions and immediate management of ADRs [8]. Similar reasons for not to report an ADR was reported in one of the attitudinal survey study [9]. It is interesting to note that majority of the physicians in our study stated that ADRs should be reported by the physicians and such reporting and monitoring system would benefit the patient. Almost all of them also agreed to the fact that drugs available in the market are not safe. Since safety of the drugs is as important as efficacy, opinion was sought from the Indian medical practitioners whether they believe all drugs available in the market are safe. Here the word "safe" meant "absolute safety" of marketed drugs in their therapeutic dose range. As a vast majority of the respondents stated 'no', they meant that they believe all marketed drugs in the country were not safe. This obviously calls for a need to be more vigilant about safety of drugs. It is further interesting to note that although they did not believe about safety or absolute safety of marketed drugs prescribed in India, yet they tend to indulge in under-reporting of ADRs. Physicians cited several reasons for under-reporting for ADRs. Inman has summarized reasons for under-reporting as the 'seven deadly sins' and his description of the 'sins' include: ignorance ('I am unsure how to report'), diffidence ('I may appear foolish about reporting a suspected ADR'), fear ('I may expose myself to legal liability by reporting an ADR'), lethargy ('I am too busy to report ADRs'),guilt ('I am reluctant to admit I may have caused harm'), ambition ('I would rather collect cases and publish them') and complacency ('only safe drugs are marketed') [10]. When less ADRs are reported, it cannot give the exact safety profile of a particular drug. India has recently launched a new programme - "Pharmacovigilance Programme of India (PVPI)". This pilot suggests that physicians in India are supportive to ADR reporting and if given the opportunity, they seek active role in pharmacovigilance. To encourage this, it is suggested to incorporate more training on pharmacovigilance to the willing physicians and emphasize more on the importance of training of reporting.

\section{Conclusion}

The PVPI should take strong steps to motivate physicians for ADR reporting in order to increase the numbers. There is an urgent need to do more research to improve the understanding of the barriers to reporting ADRs and how they may be overcome. We conclude that despite improvement of ADR reporting systems in India by launching PVPI, we still have to do lots of works to improve ADR reporting rate. For example medical staff must be encouraged for spontaneous reporting of ADRs and reporting forms must be distributed to the medical practitioners. Performing workshops and conferences with continuous medical education will increase motivation for better learning about ADRs.

\section{References}

1. Waller PC (2006) Making the most of spontaneous adverse drug reaction reporting. Basic Clin Pharmacol Toxicol 98: 320-323.

2. Lopez-Gonzalez E, Herdeiro MT, Figueiras A (2009) Determinants of underreporting of adverse drug reactions: a systematic review. Drug Saf 32: 19-31.

3. Nichols V, Thériault-Dubé I, Touzin J, Delisle JF, Lebel D, et al. (2009) Risk perception and reasons for noncompliance in pharmacovigilance: a qualitative study conducted in Canada. Drug Saf 32: 579-590.

4. Hasford J, Goettler M, Munter KH, Müller-Oerlinghausen B (2002) Physicians' knowledge and attitudes regarding the spontaneous reporting system for adverse drug reactions. J Clin Epidemiol 55: 945-950.

5. (1997) Points to consider in the manufacture and testing of monoclonal antibody products for human use (1997). U.S. Food and Drug Administration Center for Biologics Evaluation and Research. J Immunother 20: 214-243.

6. Nazl Sencan, Meryem Altınkaynak, Irmak Ferah (2010) The knowledge and attitudes of physicians and nurses towards adverse event reporting and the ef fect of pharmacovigilance training: a hospital experience. Hacettepe University Journal of the Faculty of Pharmacy 30: 25-40.

7. Rawlins MD (1995) Pharmacovigilance: paradise lost, regained or postponed? The William Withering Lecture 1994. J R Coll Physicians Lond 29: 41-49.

8. Ramesh M, Parthasarathi G (2009) Adverse drug reactions reporting: attitudes and perceptions of medical practitioners. Asian J Pharma Clin Res 2: 10-14.

9. Eland IA, Belton KJ, Van Grootheest AC, Meiners AP, Rawlins MD, et al. Attitudinal survey of voluntary reporting of adverse drug reactions. $\mathrm{Br} \mathrm{J}$ Clin Pharmacol 1999; 48: 623-27.

10. Inman WH (1996) Attitudes to adverse drug-reaction reporting. $\mathrm{Br}$ JClin Pharmacol 41: 433-435. 